Boerleider, A.W., Francke, A.L., Manniën, J., Wiegers, T.A., Devillé, W.L.J.M. "A mixture of positive and negative feelings": a qualitative study of primary care midwives' experiences with 7 non-western clients living in the Netherlands. International Journal of Nursing Studies: 2013 50(12), 1658-1666

\begin{tabular}{|l|l|}
\hline $\begin{array}{l}\text { Postprint } \\
\text { Version }\end{array}$ & 1.0 \\
\hline Journal website & $\frac{\underline{\text { http://www.journalofnursingstudies.com/article/S0020-7489(13)00125- }}}{\text { 9/abstract }}$ \\
\hline Pubmed link & $\underline{\text { http://www.ncbi.nlm.nih.gov/pubmed/23721761 }}$ \\
\hline DOI & $10.1016 / j . i j n u r s t u .2013 .04 .009$ \\
\hline
\end{tabular}

This is a NIVEL certified Post Print, more info at http://www.nivel.eu

\title{
"A mixture of positive and negative feelings": A qualitative study of primary care midwives' experiences with non-western clients living in the Netherlands
}

AgAtha W. Boerleider ${ }^{1, *}$, ANNEKe L. FranCKe ${ }^{1,2}$, JUdith MANNIEËN ${ }^{3}$, Therese A. WIEGERS ${ }^{1}$, WALTER L.J.M. DEVILLE ${ }^{\prime 1,4,5}$

${ }^{1}$. Netherlands Institute for Health Services Research (NIVEL), P.O. Box 1568, 3500 BN Utrecht, The Netherlands

${ }^{2}$ Department of Public and Occupational Health, EMGO Institute for Health and Care Research, VU University Medical Center, Amsterdam, The Netherlands

${ }^{3}$ Department of Midwifery Science, AVAG and the EMGO Institute for Health and Care Research, VU University Medical Center, Amsterdam, The Netherlands

${ }^{4}$ Faculty of Social and Behavioural Sciences, University of Amsterdam, Amsterdam, The Netherlands

${ }^{5}$ National Knowledge and Advisory Center on Migrants, Refugees and Health (Pharos), Utrecht, The Netherlands

\begin{abstract}
A B S T R A C T
Background: Non-western women living in the Netherlands are diverse in origin, which implies diversity in their needs and expectations for midwifery care. Furthermore, it has also been shown that non-western women make suboptimal use of prenatal care. Midwives may therefore face difficulties when caring for these clients. Objective: The main objective of our study was to explore Dutch primary care midwives' experiences with non-western clients. Methods: A qualitative design was used. Thirteen midwives were interviewed individually and 8 participated in a focus group. All interviews were transcribed and analysed by two researchers who compared and discussed their results. Analytical codes were organised into subthemes and main themes. Results: Midwives perceived ethnic diversity as both difficult and interesting. Caring for these women was perceived as demanding, but also rewarding. They experienced a variety of difficulties when caring for these women: communication problems, suboptimal health literacy, socioeconomic problems, lack of knowledge of the maternity care system, pressure from the family and a
\end{abstract}


Boerleider, A.W., Francke, A.L., Manniën, J., Wiegers, T.A., Devillé, W.L.J.M. "A mixture of positive and negative feelings": a qualitative study of primary care midwives" experiences with 7 non-western clients living in the Netherlands. International Journal of Nursing Studies: 2013 50(12), 1658-1666

strong preference for physicians. In spite of these difficulties, midwives aim for optimal care by being alert and proactive, taking these women by the hand and making use of alternative resources. Conclusion: Provision of care to nonwestern clients can be difficult and may require additional measures. These problems and measures should be included in midwifery education programmes as well as training programmes for midwives.

\section{WHAT IS ALREADY KNOWN ABOUT THE TOPIC?}

- Non-western women in the Netherlands are at higher risk for adverse pregnancy outcomes and make less optimal use of prenatal care.

- Maternity care providers in other industrialised western countries have encountered communication problems, lack of familiarity with the healthcare system and cultural differences among ethnic minority women.

- Maternity care providers use alternative methods of communication when caring for non-western women.

\section{WHAT THIS PAPER ADDS}

- Primary care midwives’ feelings about caring for non-western women are ambivalent. They perceive this care as difficult, but also containing positive aspects such as satisfaction.

- Primary care midwives try to ensure the health of non-western mothers and children by being alert and proactive, taking their clients and families by the hand and making use of alternative resources.

\section{INTRODUCTION}

Migration to the more developed regions of the world has shown a rising trend over the past years. The proportion of migrants worldwide living in more developed regions of the world increased from 53\% in 1990 to 60\% in 2010. Female migrants exceeded male migrants in number and comprised $51.5 \%$ of the migrant population in these regions (United Nations Population Division). Several studies conducted in developed countries have shown that the needs and expectations of migrants in terms of maternity care are not always met by the healthcare system (Hoang et al., 2009; Murray et al., 2010; Reitmanova and Gustafson, 2008). Healthcare systems tend to focus their care mainly on the majority population and are not responsive enough to the ethnic diversity within the client population (Cioffi, 2003; Hoang et al., 2009). In the Netherlands, $11.4 \%$ of the population in 2011 was of non-western migrant origin, in the sense that at least one parent was born in Africa, Asia, Latin America or Turkey. Data from 2010 show that non-western women contributed 17.7\% of all live births (Statistics Netherlands Statline). In the three major cities of the Netherlands Amsterdam, Rotterdam and The Hague - they in fact contributed 47, 48 and 42\% of the births respectively (de Graaf et al., 2008). It can be concluded from this data that Dutch midwives, especially those working in the major cities, are providing care to a client population of which a substantial part is non-western in origin. These nonwestern clients are very diverse in origin, with Turks, Moroccans, Surinamese and Antilleans/Arubans comprising the largest groups in the Netherlands. This diversity in country of origin implies a diversity in cultural backgrounds and hence a variety of 
Boerleider, A.W., Francke, A.L., Manniën, J., Wiegers, T.A., Devillé, W.L.J.M. "A mixture of positive and negative feelings": a qualitative study of primary care midwives' experiences with 7 non-western clients living in the Netherlands. International Journal of Nursing Studies: 2013 50(12), 1658-1666

needs and expectations regarding maternity care. The Royal Dutch Organization of Midwives (KNOV) attaches great importance to placing women at the centre of care. This implies that midwives have to take the cultural background and the specific needs and expectations of their clients into account.

Non-western clients have also been shown to make suboptimal use of prenatal care compared to the majority population of the Netherlands (Alderliesten et al., 2007; Choté et al., 2011). This less than optimal use is mainly characterised by late start of prenatal care, and may delay detection and treatment of pregnancy complications, concurrent illnesses and health problems. Two Dutch studies have reported that the late start of prenatal care explains at least part of the high perinatal mortality observed among certain non-western groups (Alderliesten et al., 2008; Ravelli et al., 2011). Furthermore, non-western clients have been shown to be at higher risk of maternal mortality and congenital disorders (Waelput and Achterberg, 2007). Thus, both the suboptimal use of prenatal care and the different needs and expectations may complicate the provision of optimal care to non-western clients who are at greater risk for poor pregnancy outcomes.

Only a few studies in developed countries have explored the experiences of midwives or other maternity care providers with women from ethnic minorities. In a survey conducted among midwives in Spain, $67 \%$ of the 102 respondents stated that language barriers were a key difficulty in providing health education to African women (Goberna-Tricas et al., 2005). Fifty-four per cent of the respondents used additional materials such as books, videos and leaflets to educate these women. In the UK, maternity care professionals were interviewed about their perceptions of the effect that ethnic background, social status and class have on service delivery for UK-born ethnic minority women (Puthussery et al., 2008). The maternity care professionals perceived UK-born ethnic minority women to be more assertive and to have better language proficiency and better comprehension of the healthcare system than ethnic minority women born elsewhere. In an ethnographic study carried out in a British hospital, midwives were found to have stereotypical ideas about South Asian women that were used to make decisions about the care these women want, need and deserve (Bowler, 1993). These stereotypes were centred on four themes: communication problems, lack of compliance with care and misuse of services, making a fuss about nothing, and a lack of maternal instinct. In a qualitative study conducted in Ireland, communication difficulties, cultural differences and suboptimal knowledge and use of services were some of the main issues raised by maternity service providers about ethnic minority women (Lyons et al., 2008). In another qualitative study conducted in Canada, health care providers reported several differences in expectations between them and immigrant clients: language, cultural competency, the type of care provided and the medicalisation of pregnancy ( $\mathrm{Ng}$ and Newbold, 2011). A focus group study conducted in Norway revealed that midwives and public health nurses encountered health challenges and cultural challenges when caring for migrant women (Lyberg et al., 2012). The first three studies each focused specifically on a certain aspect of experiences with ethnic minority women: communication, the effect of the migrant's background, social status and class on service delivery or stereotypes. Only the remaining three studies considered various aspects of maternity care providers' experiences with ethnic minority women. These studies were conducted in Ireland, Canada and Norway, countries with a different migration history and different migrant groups than the Netherlands. Furthermore, 
Boerleider, A.W., Francke, A.L., Manniën, J., Wiegers, T.A., Devillé, W.L.J.M. "A mixture of positive and negative feelings": a qualitative study of primary care midwives' experiences with 7 non-western clients living in the Netherlands. International Journal of Nursing Studies: 2013 50(12), 1658-1666

the maternity care system in the Netherlands is unique, with primary care midwives being the lead professionals providing care to women with uncomplicated pregnancies and births (Wiegers and Hukkelhoven, 2010). Dutch primary care midwives may have different experiences with non-western clients, so we decided to conduct a sub study within a national midwifery study to look at their experiences. The following questions are addressed in this article:

1) What specific issues do primary care midwives in the Netherlands experience in their working relationship with non-western clients?

2) Do these primary care midwives adjust their care for non-western clients and if so in what way?

\section{METHODS}

A generic qualitative approach was used, implying that not one specific qualitative methodology was used as guidance, and that a declaration of the researcher's position, congruence between methodology and method, a clear articulation of the researcher's approach to rigour and an explanation of the analytic lens are provided (Caelli et al., 2003). Our interest in the subjective experiences and perceptions of midwives providing care to non-western clients meant that holding qualitative interviews seemed most suitable. We conducted both individual interviews and a focus group interview with midwives, letting these two methods complement each other. Particularly delicate topics might be more readily discussed in individual interviews, whereas for other topics this might be the case in a group interview, where there is a more dynamic interaction between participants.

\subsection{Recruitment and sample}

\subsubsection{The individual interviews}

Initially, convenience sampling was carried out by recruiting midwives from the 20 midwifery practices participating in the national DELIVER study, a large research project in the Netherlands focusing on the quality, organisation and accessibility of primary care midwifery in the Netherlands (Manniën et al., 2012). The representatives of these midwifery practices to the DELIVER study were all approached. Eight practices were willing to participate: four by their representative and four by another midwife of the practice. The main reasons that the remaining twelve practices gave for declining to participate were few or no non-western clients or being too busy.

During the course of data collection, purposive sampling was adopted. Midwives taking a compulsory training course for intercultural midwifery care organised by their employers were approached at the end of the training by the first author, who also gave a presentation about her study during the training course. Nine midwives showed interest and were later approached by e-mail. In the end, two were willing to be interviewed. To achieve variation in our sample, final recruitment was targeted at specific categories of midwives, such as those with little work experience. Three midwives from these target categories were recruited via midwifery researchers. 
Boerleider, A.W., Francke, A.L., Manniën, J., Wiegers, T.A., Devillé, W.L.J.M. "A mixture of positive and negative feelings": a qualitative study of primary care midwives" experiences with 7 non-western clients living in the Netherlands. International Journal of Nursing Studies: 2013 50(12), 1658-1666

Interested midwives received an information letter by e-mail. Those willing to be interviewed made an appointment by e-mail or telephone with the first author. Individual interviews were held with thirteen midwives. The midwives were all women, aged between 23 and 58. Eleven were of native Dutch origin and two of non-western origin. All the midwives were qualified to work in the Netherlands. Twelve of them were practising in primary care, while one was practising four years in secondary care after having worked for three years as a primary care midwife. As we were interested in the experiences of primary care midwives, the interview with this last midwife focused only on her experience in primary care. Ten midwives were practising in urban areas, which are known to have large numbers of non-western clients, whereas three midwives were practising in rural areas. Their experience with non-western clients ranged from 11 months to 19 years.

All individual interviews (likewise the focus group interview, see below) were conducted by the first author; a female Dutch researcher whose interest in this topic was awakened by her own non-western (Surinamese) background. She studied medicine and public health, and had a training in qualitative research methods in medical anthropology. She presented herself as a researcher to the interviewees, who were all unfamiliar to her before-hand. Interviewees were explained that the interviews were conducted as part of a larger study exploring factors affecting midwifery care utilisation by non-western women in the Netherlands.

\subsubsection{The focus group interview}

For the focus group, the head of a regional midwifery group (Verloskundigen Kring) located in an urban area was asked permission to hold a small focus group within one of the group's regular meetings. A total of 8 primary care midwives were present at this regional midwifery meeting, which we were allowed to attend. They were all females of native Dutch origin, aged between 28 and 58, whose experience with nonwestern clients ranged from 6 to 19 years.

\subsection{Interviews; data collection}

\subsubsection{The individual interviews}

A semi-structured topic list was used to guide the interviews, although the interviewees were also encouraged to raise issues that were relevant to them but not included in the topic list. As Dutch midwives provide care in the prenatal, natal and postnatal periods, the list explored their experiences in all these three stages of care. It was reviewed by six research experts (including two midwives) and was drawn up using existing literature and the model of Foets et al. The latter is an elaboration of the Andersen model of healthcare utilisation in which ethnic differences in healthcare use are explained by various underlying factors such as migration-related characteristics, cultural factors, socioeconomic status, social network, accessibility of healthcare, personal treatment by healthcare professionals and communication (Foets et al., 2007). Prior to data collection, the topic list and semistructured interview style were tested in a pilot interview with a midwife.

The interviews were conducted in Dutch, varying in length between approximately 60 and $90 \mathrm{~min}$. They were conducted at the preferred location of the midwives: eleven in the midwifery practice, one at the coordinating health centre to which the 
Boerleider, A.W., Francke, A.L., Manniën, J., Wiegers, T.A., Devillé, W.L.J.M. "A mixture of positive and negative feelings": a qualitative study of primary care midwives' experiences with 7 non-western clients living in the Netherlands. International Journal of Nursing Studies: 2013 50(12), 1658-1666

midwifery practice was connected, and two at home. The number of midwives to be interviewed was not predetermined. Interviewing was continued until data saturation was attained, i.e. the point at which no new information or themes were observed in additional data (Guest et al., 2006).

\subsubsection{The focus group interview}

The focus group was conducted after finalisation of the individual interviews. Like the individual interviews, it was guided by a semi-structured topic list and participants were also encouraged to bring forward any other relevant information. The topic list also covered all three stages of care and focused on the subthemes and main themes that emerged from the individual interviews.

The focus group was conducted in Dutch and lasted approximately $35 \mathrm{~min}$ due to time constraints of the midwives. An assistant was responsible for audiotaping the interview and taking notes. The focus group was conducted in the meeting room of a healthcare organisation.

\subsection{Analyses of the data from the individual interviews and the focus group interview}

The audiotapes of each individual interview and the focus group interview were transcribed fully and verbatim. Analysis of the individual interviews was part of a cyclic process of data collection and data analysis. Shortly after each conducted interview, the first author read the transcript several times and listened to the audiotape. Subsequently each interview was analysed thematically (Green and Thorogood, 2009). Each of the co-authors independently analysed two or three interviews as well, whereupon they discussed their results with the first author. As the data collection and analysis progressed, new transcript sections were assigned an existing or new code, while some already coded transcript sections were recoded into more meaningful codes. Also, codes were combined and recombined into subthemes and overarching main themes (such as having a mixture of positive and negative feelings) which were also discussed with the co-authors. To improve the reliability of the analysis, the software program MAXQDA (MAXQDA, 2007 Introduction) was used to support the coding and ordering of the interview material.

To assess the credibility of our findings, the final subthemes and main themes were discussed in a group session of a Dutch midwifery care conference and with several individual midwives.

\subsection{Ethical aspects}

This study was carried out as part of the mentioned national DELIVER study, which obtained ethical approval from the medical ethics committee of the VU University Medical Center in the Netherlands. All interviewees from the individual interviews and focus group received written and verbal information about the aim and content of the interviews, whereupon they individually gave written informed consent to be interviewed and audiotaped. The researcher promised confidential handling of the interview data and affirmed this by signing the confidentiality agreement on each interviewees' consent form. 
Boerleider, A.W., Francke, A.L., Manniën, J., Wiegers, T.A., Devillé, W.L.J.M. "A mixture of positive and negative feelings": a qualitative study of primary care midwives" experiences with 7 non-western clients living in the Netherlands. International Journal of Nursing Studies: 2013 50(12), 1658-1666

\section{RESULTS}

Several themes could be identified in the experiences of midwives providing maternity care to non-western clients. These aspects were categorised into three main themes: (1) Having a mixture of positive and negative feelings, describing the feelings midwives have about caring for non-western clients, (2) Facing challenges in the provision of care, describing the difficulties midwives experience when providing care to non-western clients, (3) Aiming for optimal care in the interests of both mother and child, describing the efforts and adjustments midwives make to guarantee good quality care for non-western clients and their babies.

\subsection{Having a mixture of positive and negative feelings about caring for non- western women}

All the midwives expressed feelings about caring for non-western women; some very outspoken, others less so. These feelings were best described as a mixture of positive and negative feelings, and concerned both the ethnic diversity and workload.

\subsubsection{Finding the ethnic diversity fascinating but also quite difficult}

All the midwives liked the ethnic diversity in their client population and perceived differences in customs and traditions surrounding pregnancy and birth as fascinating and interesting. Some midwives spontaneously stated that working in a midwifery practice with non-western clients and thus having a variety of cultural backgrounds among their client population was a deliberate choice and that they would not want to miss it. Simultaneously with feelings of fascination and interest in non-western clients, midwives also encountered less pleasant feelings. Some non-western clients were also experienced as difficult, particularly those not proficient in Dutch. Communicating with these clients was perceived to be more awkward.

People who can handle the language well enough. . . yes that's fine, no problem. They're like anyone else and then it's nice to notice the differences and deal with them. It gets a bit difficult with people who don't speak the language. You have to use the telephone interpreter then. And dealing with asylum seekers: I thought I would really like that but I don't, because it often doesn't go smoothly. I find that tricky. (R5)

In a few cases, midwives even expressed feelings of frustration and irritation along with feelings of fascination and interest.

Interesting, difficult. . . sometimes demanding, especially in terms of time and giving explanations. Don't get me wrong: I wouldn't want to miss it. Sometimes it frustrates me so much that I think, "My God, why am I working in a region like this [with a lot of migrant clients].” But I think I'd be very unhappy if I wasn't. In that sense, I am grateful. (R1) 
Boerleider, A.W., Francke, A.L., Manniën, J., Wiegers, T.A., Devillé, W.L.J.M. "A mixture of positive and negative feelings": a qualitative study of primary care midwives" experiences with 7 non-western clients living in the Netherlands. International Journal of Nursing Studies: 2013 50(12), 1658-1666

\subsubsection{Having a demanding but also rewarding job}

When talking about the workload associated with non-western clients, a clear difference was noticed between practices with many non-western clients and those with just a few. Midwives working in urban practices with a lot of non-western clients indicated clearly that caring for some of these clients was very demanding. Some midwives working in rural areas with few non-western clients said the same, but reckoned it was manageable. They explained that the small number of nonwestern clients meant that the work was not experienced as very demanding, whereas it would have been if they had more non-western clients.

The main reasons mentioned by the midwives for the work being so demanding were the language barrier, a lack of knowledge of the Dutch maternity care system and the low socioeconomic status. A few midwives even felt that sometimes they were virtually in the role of a cleaning lady or police officer, as they sometimes had to do some cleaning at women's home or had to be vigilant to make sure that additional examinations such as laboratory tests were conducted.

Although midwives experienced caring for non-western clients as demanding on the one hand, they also experienced caring for them as rewarding on the other. Several midwives said that satisfaction after caring for non-western clients was high, especially when they were able to solve problems encountered during maternity care.

She had given birth in the hospital, a short-stay hospital birth. The next day, I went for a postnatal checkup. She had not arranged maternity care assistance; the whole house was dirty and the child was lying on the floor. I then had to arrange everything: maternity care assistance and the general practitioner (GP). Social work too, because she had three children, her house was not clean and she had told me she didn't have any money. So it all had to be arranged straight away, and so you lose a whole day. I could also have said I wasn't going to do it and only arranged maternity care assistance, but social services need to know that this woman has had her third child and that she's at home. [. . .] Once everything was arranged, I could leave. But it takes a lot of time. Not everybody is as easily accessible as the midwife, especially GPs. You can't phone them in the afternoon. [...] and then you have to arrange it the next day. It also gives a lot of satisfaction, because then you're thinking, "'Okay, I've been very busy; all the problems have been solved and it's all fine." (R13)

\subsection{Facing difficulties in the provision of care}

Various difficulties in the provision of care to non-western clients were reported by midwives. These problems could be organised into two main groups: practical challenges that complicate the provision of care, and different cultural values that cannot always be met or may interfere with the provision of care. These difficulties were more pronounced among non-western clients born outside the Netherlands, compared to those born in the Netherlands. 
Boerleider, A.W., Francke, A.L., Manniën, J., Wiegers, T.A., Devillé, W.L.J.M. "A mixture of positive and negative feelings": a qualitative study of primary care midwives' experiences with 7 non-western clients living in the Netherlands. International Journal of Nursing Studies: 2013 50(12), 1658-1666

\subsubsection{Facing practical difficulties}

Communication problems and suboptimal health literacy. Communicating with clients who do not have a good command of Dutch was described as difficult by midwives. This was especially the case during telephone conversations, when it was not possible to use alternative means of communication such as telephone interpreters. Besides communication problems, midwives are also confronted with health literacy problems. The impact of a limited ability to read, understand and use health information was clear in the utilisation of maternity care by some clients. Notifying the midwife in the event of delayed or missed appointments, attending appointments for laboratory or ultrasound examinations outside the midwifery practice, attending group meetings about childbirth, and applying for postnatal care do not always go smoothly.

Sometimes I find it frustrating when I can't express myself to other people because of a language barrier. That sometimes makes it difficult to explain what you mean, and so you sometimes also get the feeling that maybe you are holding things back from them.. even if you're trying really hard with an iPod or Google Translate. (F)

The second generation often speaks Dutch reasonably or very well. But there are still people from the second generation who have trouble with Dutch and then. .. When they can speak a bit of Dutch or a bit of English, it can be dangerous. We think, "Okay, we can communicate"- but then it sometimes turns out that they didn't understand. (R4)

And it's sometimes awkward with laboratory examinations, because then we have to explain that they need to go somewhere else at a certain time or for their next appointment, for example. That doesn't always happen. They may have forgotten, or not understood us, or only handed in one of the two forms given to them so we receive only half the results. But if they have someone with them who does understand, someone who understands the language and goes along with them to take care of things, then it goes very well. (R9)

Lack of knowledge of the maternity care system. The second practical problem midwives reported was limited knowledge of the Dutch maternity care system. Nonwestern clients, especially those not born in the Netherlands, do not always understand the role of primary care midwives and sometimes are surprised to hear that uncomplicated pregnancies and births are supervised by midwives. The appointments system in midwifery practices is also not always understood. Nonwestern clients are more often late for appointments, but often assume that they will still be seen by a midwife. When that is not possible and a new appointment needs to be made, they do not always understand. Another area where knowledge is lacking concerns the place of birth. They are not always aware that they can choose to give birth either at home or during a short stay at the hospital under the supervision of the primary care midwife (if they have a low risk of complications) and sometimes expect an obstetrician to lead these short stay hospital births. When the midwife informs non-western clients about postnatal care by maternity care assistants, it sometimes becomes clear that the importance of this and the application procedure 
Boerleider, A.W., Francke, A.L., Manniën, J., Wiegers, T.A., Devillé, W.L.J.M. "A mixture of positive and negative feelings": a qualitative study of primary care midwives' experiences with 7 non-western clients living in the Netherlands. International Journal of Nursing Studies: 2013 50(12), 1658-1666

are not always understood. This lack of knowledge of the maternity care system is sometimes also seen among partners of clients, who try to insist on care being provided as they expect it to be.

Sometimes we assume that people know how it works at a birth, but there are a lot of people planning a short-stay hospital birth who think, "Now we're going to the hospital and we'll be looked after by someone else." And sometimes they're surprised to see that we [the midwives] go along with them, "Hey, aren't we going to the hospital?", "But I'll still be supervising your labour and the birth.” - "'Oh, that's nice.” Then they're very happy. Or that we'll visit them in the first week after giving birth. They don't always know that we'll come along to their home and do some checkups. They think, "It all ends with the birth and then the maternity care assistant takes over, and I won't see the midwife anymore." And when we tell them after the birth that we'll see them tomorrow, they think: “Tomorrow?"' And that's apparently some- thing else they don't know. We do tend to assume they know, but it's not always the case. (R10)

The impact of socioeconomic status. The midwives indicated that they encountered socioeconomic problems among native Dutch clients as well as non-western clients. However, a few midwives did state that they encountered these issues more frequently among non-western clients in their working region. Some difficulties concerned midwifery care directly, e.g. not being able to buy the necessities for the delivery and the baby, lack of transportation options to the midwifery practice or the hospital in the case of a short-stay hospital delivery or lack of prepaid credit to telephone the midwife in the event of an emergency. Other problems influenced midwifery care more indirectly, such as debts or domestic violence. These situations often require other services such as maternity care assistance and social work to be informed and sometimes collaborated with.

If you are working here in XXX, and you go to native Dutch family with two incomes, you'll find nappies in different colours. If you go to immigrant families [...] She was having a home birth, and was from Suriname I think. She was here illegally; it was her fifth child, and she didn't have anything at home. So we had to fill cola bottles with warm water and wrap them in clothes to keep the baby warm. She didn't have anything. She did not have a chair, nor absorbent nappies. Luckily we had spares of everything in our car. And she gave birth on the floor. It went beautifully, the birth was beautiful, but the contrast was huge. (R13)

Well, because that population [low socioeconomic status] requires much more collaboration. It requires more collaboration with other disciplines such as social work, gynaecologists and GPs. And that's difficult, because there are an awful lot [of disciplines]. (R12)

\subsubsection{Being confronted with different cultural values}


Boerleider, A.W., Francke, A.L., Manniën, J., Wiegers, T.A., Devillé, W.L.J.M. "A mixture of positive and negative feelings": a qualitative study of primary care midwives" experiences with 7 non-western clients living in the Netherlands. International Journal of Nursing Studies: 2013 50(12), 1658-1666

Pressure from the family. Midwives reported close involvement of the families, with the exception of refugees and asylum seekers who often do not have many family members around. This is especially apparent during the postnatal period, when family members come to stay with the new mother and take over domestic chores. As well as taking over domestic chores, the family also gives a lot of advice and information to the new mother. Most of this advice is culturally based and innocent enough, but in a few cases it can contradict the advice of healthcare professionals. In these instances, it is not always easy for midwives to convince the clients and their families about the potential hazards of certain practices.

And then I said, “no, no, you really shouldn't do that.” The mother-in-law didn’t understand Dutch, and so I said to the mother, "You must absolutely not do this. It is very dangerous,'” and I explained the danger to her. Then they called me at night. "Help, the child..." They had indeed given honey to the baby. Yeah. . . that happens sometimes. The mother in law, the way she looked at me. . . She looked at me like: you're not telling me anything, I'm older than you are, you don't have to tell me what's wise. I could see it in her eyes. You can feel that you're not being taken seriously. (R1)

Strong preference for physicians. Although Dutch midwives are autonomous medical practitioners, qualified to provide full maternity care under their own responsibility to all women with an uncomplicated pregnancy and childbirth, many midwives recognised a strong belief in physicians among their non-western clients. The midwives sometimes referred to this belief in doctors as believing in "the impression of the white coat'". They talked about situations where non-western clients were anxious or worried about the pregnancy or the coming birth. In some of these cases, the clients could only be reassured by consulting an obstetrician who could convince them that everything was okay.

You notice that some people find it very pleasant to come here. They really like the fact that we are women and also emphasise it. But at the same time, they'd [some people] actually also like it if we wore white coats - that would be even better, so to speak. The white coat is actually part of it. Therein lies the duality sometimes, I think. There are still a lot of people who only feel they are being taken seriously when they are referred to a hospital or when they are in hospital. (R8)

\subsection{Aiming for optimal care in the interests of both mother and child}

Even though midwives sometimes experienced challenging situations in the provision of care to non-western clients, they all talked about their willingness and efforts to achieve optimal care in the interests of mother and child.

\subsubsection{Being alert and proactive}

One of the ways some midwives tried to achieve optimal care for non-western clients was by being alert. They do this by asking clients to recite the information given to them, checking whether they have the necessities for childbirth and the baby, 
Boerleider, A.W., Francke, A.L., Manniën, J., Wiegers, T.A., Devillé, W.L.J.M. "A mixture of positive and negative feelings": a qualitative study of primary care midwives' experiences with 7 non-western clients living in the Netherlands. International Journal of Nursing Studies: 2013 50(12), 1658-1666

keeping an updated overview of clients who have missed appointments and checking clients' knowledge of the Dutch maternity care system. Some midwives also try to be proactive. Clients who do not show up for appointments are called and asked to explain the reason for missing the appointment and to make a new appointment. In cases of language difficulties, extra time is reserved for consultations. Because of anticipated difficulties in locating the laboratory or ultrasound clinic, clients may be given a printout from a route planner. In the case of a client with lower socioeconomic status, some midwives call the maternity care agency and ask them to assign an experienced maternity care assistant to these clients. Some midwives also place additional emphasis on the benefits of breastfeeding to clients who prefer formula feeding but cannot afford it. The midwives also described how they were more likely to pay home visits to clients with whom they had difficulty communicating by telephone.

My personal experience is that it's best to pay them a home visit. I often came across some big problems by paying them a home visit. They sometimes called for something that did not seem really urgent, but when I went on a home visit, I came across something very urgent. The information I got from them wasn't complete. So most times I thought, 'I'll just pay them a home visit, and then I am reassured that everything is okay.” (R13)

\subsubsection{Taking them by the hand}

The midwives were also confronted with situations where non-western clients had received care in their native country. These clients sometimes expect the same kind of care in the Netherlands, e.g. more laboratory investigations or more ultrasound scans. In these situations, midwives have to spend extra time explaining the Dutch maternity care system, the leading role of the midwife during uncomplicated pregnancies and childbirth, and the importance of postnatal care to these clients.

Well, most people are quite well aware of how it works. It also depends a bit on how big their network of family or friends is in the Netherlands. I guess they tell each other how it works. And if you have a very small network, you have no idea where to go. So, you always need to kind of check how much people actually know. I mean, she'll probably know that she needs to visit you for checkups, but may have no idea what the maternity care assistant does and may sometimes be a bit reluctant because they think, "Well, my mother-inlaw will come and do all the housework. So then you have to invest extra time explaining that the maternity care assistant has more functions than just cleaning the house. (R2)

\subsubsection{Using alternative methods of communication}

All the midwives talked about using alternative methods of communication. Several midwives said that telephone interpreting is essential in their work with non-western clients. Even if clients bring someone along as an interpreter, it is not always possible or appropriate to discuss everything with these lay interpreters. Telephone interpretation is preferred when discussing sensitive issues or providing important 
Boerleider, A.W., Francke, A.L., Manniën, J., Wiegers, T.A., Devillé, W.L.J.M. "A mixture of positive and negative feelings": a qualitative study of primary care midwives' experiences with 7 non-western clients living in the Netherlands. International Journal of Nursing Studies: 2013 50(12), 1658-1666

instructions to make sure that the client under- stands the instructions, e.g. at the beginning and at the end of childbirth. Other resources used are translated leaflets with important information about prenatal screening, preparing for childbirth and coping with pain. These leaflets can be found in various languages on the websites of the National Institute for Public Health and the Environment (RIVM) and the Royal Dutch Organization of Midwives (KNOV). The Internet was also used to show nonwestern clients films about childbirth. In addition to the Internet, midwives also use pictures, drawings and non-verbal communication in their contact with non-western clients who do not have sufficient command of the Dutch language.

My experience when we use telephone interpretation is that we see people perk up when they are addressed in their own language. You can use hands and feet and ask if the baby is moving well, but now she can really tell me how it is. And I must say that this always encourages me to use this method when I see what it does to people. (R7)

\section{DISCUSSION}

This study aimed to explore the experiences of primary care midwives with nonwestern clients in the Netherlands. Data were collected through individual interviews and a focus group. Three main themes emerged from the analysis: having a mixture of positive and negative feelings, facing difficulties in the provision of care and aiming for optimal care in the interests of mother and child.

The mixture of positive and negative feelings sheds new light on the experiences of care providers with non-western clients. Whereas studies conducted previously had described negative feelings such as frustration (Cioffi, 2003; Dalheim-Englund and Rydström, 2012; Murphy and Macleod-Clark, 1993) and the difficulties encountered, this study revealed that the midwives interviewed also derive positive feelings such as satisfaction from working with non-western clients.

The difficulties faced in providing care are consistent with the results of studies conducted in other western countries among midwives or other maternity care providers. These studies also reported communication problems (Goberna-Tricas et al., 2005; Lyberg et al., 2012; Lyons et al., 2008; Ng and Newbold, 2011), limited knowledge of the healthcare system (Puthussery et al., 2008), family involvement (Puthussery et al., 2008) and preference for physicians (Ng and Newbold, 2011). Studies conducted among other health professionals have also reported communication problems (Hultsjö and Hjelm, 2005; Murphy and Macleod-Clark, 1993; Priebe et al., 2011), lack of knowledge of the healthcare system (Priebe et al., 2011) and social deprivation (Priebe et al., 2011) as issues when caring for nonwestern clients. Like the study by Puthussery et al., we also found that those who were proficient in Dutch - mostly second generation migrants - were often perceived as less problematic. According to the model of Foets et al. (2007), these factors may affect healthcare utilisation. It may be argued that as the topic list was drawn upon the model of Foets et al., it could be expected that the experienced difficulties would emerge as themes in this study. However, the other themes found in this study refute this argument, as they are not described in the model of Foets et al. 
Boerleider, A.W., Francke, A.L., Manniën, J., Wiegers, T.A., Devillé, W.L.J.M. "A mixture of positive and negative feelings": a qualitative study of primary care midwives' experiences with 7 non-western clients living in the Netherlands. International Journal of Nursing Studies: 2013 50(12), 1658-1666

Language difficulties may affect the care given to clients and may also contribute to stereotyping behaviour by care providers who interpret these difficulties differently (Robinson and Gilmartin, 2002). Use of alternative resources such as telephone interpretation, family members or friends as interpreters and translated leaflets is very helpful (Cioffi, 2003; Jirwe et al., 2010) but these resources are not always available and suitable. From 1 January 2012, the Dutch Ministry of Health, Welfare and Sports stopped the reimbursement for use of interpretation services in healthcare (Schippers and Veldhuijzen van Zanten-Hyllner, 2011). This decision was justified by placing the responsibility for a command of the Dutch language on the clients and their representatives. This may lead to less use of interpretation services, which may impede clients' ability or willingness to take an active role. Moreover, midwives' efforts to achieve optimal care in the interests of mother and child may be made more complex.

Lack of knowledge may not only affect clients' use of care, but also their expectations. This is seen when care in the Netherlands is compared to care in their native country. The Netherlands has a unique system of independently working midwives, and lack of familiarity with this unique maternity care system may explain the strong reliance on physicians by some non-western clients. Socioeconomic problems may affect the care given to clients. In this study, midwives particularly found contacting and collaborating with other institutions such as social services to be a very time-consuming aspect of care. In the task description of primary care midwifery in the Netherlands, caring for clients with a low socioeconomic status (including clients of migrant origin) was reported to require $23 \%$ more time for all healthcare activities (Reitsma et al., 2007). Since 1 January 2009, the Dutch Healthcare Authority (NZa) has implemented an extra fee for midwives working in socially deprived neighbourhoods, but not all the clients who require greater effort live in these neighbourhoods. This means that midwives are not always reimbursed for their additional efforts.

Limited literacy among some non-western clients may create difficulties in the provision of care. Clients' ability or willingness to take an active role in their own care may be hampered (Silow-Carroll et al., 2006). This also applies for the language barrier and the socioeconomic problems. Furthermore, limited knowledge of the maternity care system may also impede clients' ability to take an active role, as the clients may not be familiar with this approach in their country of origin. In the present study it was found that midwives had to take over this active role to ensure optimal care in the interest of both mother and child. This more active role was expressed by being alert and proactive, taking these women by the hand and utilising alternative resources. This more alert and proactive approach adds to the existing literature on the experiences of midwives and other maternity care providers with non-western clients.

\subsection{Strengths and limitations}

One of the strengths of this study is its originality. To our knowledge, this study is the first to explore the experiences with non-western clients in Dutch midwifery care setting. Also, the combination of individual and focus group interviews, using these two methods to complement each other may be considered a strength. A limitation of this study might be that the researcher who conducted all the interviews is of non- 
Boerleider, A.W., Francke, A.L., Manniën, J., Wiegers, T.A., Devillé, W.L.J.M. "A mixture of positive and negative feelings": a qualitative study of primary care midwives' experiences with 7 non-western clients living in the Netherlands. International Journal of Nursing Studies: 2013 50(12), 1658-1666

western origin. This might have influenced the interviews in that midwives might then have expressed their experiences with non-western clients more cautiously in order not to be accused of discrimination or racism. Nevertheless, this did not deter them from expressing negative feelings. A second limitation might be the focus group participants who knew each other. This may have caused participants to withhold certain experiences from their colleagues and therefore from the focus group. On the other hand, this may have facilitated the discussion because they already knew each other.

\subsection{Implications}

The insights gained in this study point into the direction that the training for midwives and midwifery practice in the Netherlands and other countries with large non-western populations needs to be adapted. The difficulties midwives face with non-western clients may affect the quality of care if there is no proper response. The experiences of midwives make clear that they have all developed their own ways of coping with these issues. As midwifery students will be confronted with the same challenges as current midwives, the difficulties faced and the responses to them should be included in midwifery education programmes. Future mid- wives will then be better prepared for working with non-western clients and will take a creative approach towards the difficulties encountered. In addition to midwifery colleges, midwifery organisations could also benefit from the findings in this study by developing training programmes for pooling and sharing existing strategies for dealing with these clients. Furthermore, there are also implications for the government and healthcare insurers. The financing for longer consultations, home visits and telephone consultations needs to be considered, especially where midwives are not receiving an extra fee in cases of clients who do not live in socially deprived areas. Also, stopping the reimbursement for interpretation services might have a negative impact on the quality of care provided by midwives to non-western clients and should therefore be reconsidered. Finally, future research on non-western women's perspective on midwifery care is needed to gain a more complete picture of how midwives support non-western clients.

\section{CONCLUSIONS}

The study results indicate that midwives see providing care to non-western clients as difficult and demanding, but simultaneously as fascinating and rewarding. As midwives aim for optimal care in the interests of both mother and child, they take a variety of additional measures, some of which they have invented themselves. The quality of midwifery care might be improved by collecting these measures and including them in midwifery education programmes and training programmes for midwives.

\section{Conflict of interest}

The authors declare to have no competing interest. 
Boerleider, A.W., Francke, A.L., Manniën, J., Wiegers, T.A., Devillé, W.L.J.M. "A mixture of positive and negative feelings": a qualitative study of primary care midwives' experiences with non-western clients living in the Netherlands. International Journal of Nursing Studies: 2013 50(12), 1658-1666

\section{Funding}

The Academy of Midwifery Amsterdam-Groningen (AVAG) and the Dutch Ministry of Education, Culture and Science.

\section{Ethical approval}

This study was carried out as part of the mentioned national DELIVER study, which obtained ethical approval from the medical ethics committee of the VU University Medical Center in the Netherlands (WC 008-100).

\section{Acknowledgements}

We would like to thank the midwives who participated in this study. We would also like to acknowledge the contributions by Trudy Klomp, Fuusje de Graaff, Janneke Gitsels and Carien Baas to the recruitment process for this study.

\section{REFERENCES}

Alderliesten, M.E., Vrijkotte, T.G., van der Wal, M.F., Bonsel, G.J., 2007. Late start of antenatal care among ethnic minorities in a large cohort of pregnant women. BJOG: An International Journal of Obstetrics and Gynaecology 114 (10) 1232-1239.

Alderliesten, M.E., Stronks, K., van Lith, J.M., Smit, B.J., Wal, M.F., Bonsel, G.J., Bleker, O.P., 2008. Ethnic differences in perinatal mortality. A perinatal audit on the role of substandard care. European Journal of Obstetrics and Gynecology and Reproductive Biology 138 (2) 164-170.

Bowler, I., 1993. 'They're not the same as us': midwives' stereotypes of South Asian descent maternity patients. Sociology of Health and Illness 15 (2) 157-178.

Caelli, K., Ray, L., Mill, J., 2003. 'Clear as mud': toward greater clarity in generic qualitative research. International Journal of Qualitative Methods 2 (2) 1-24.

Choté, A.A., de Groot, C.J., Bruijnzeels, M.A., Redekop, K., Jaddoe, V.W., Hofman, A., Steegers, E.A., Mackenbach, J.P., Foets, M., 2011. Ethnic differences in antenatal care use in a large multi-ethnic urban population in the Netherlands. Midwifery 27 (1) 36-41.

Cioffi, J., 2003. Communicating with culturally and linguistically diverse patients in an acute care setting: nurses' experiences. International Journal of Nursing Studies 40 (3) 299-306.

Dalheim-Englund, A.C., Rydström, I., 2012. "I have to turn myself inside out": caring for families of children with asthma. Clinical Nursing Research 21 (2) 224-242.

de Graaf, J.P., Ravelli, A.C.J., Wildschut, H.I.J., Denktas, S., Voorham, A.J.J., Bonsel, G.J., Steegers, E.A.P., 2008. Perinatal outcomes in the four largest cities and in deprived neighbourhoods in The Netherlands. Nederlands Tijdschrift voor Geneeskunde 152 (50) 2734-2740.

Foets, M., Suurmond, J., Stronks, K., 2007. De relatie tussen etnische herkomst en gezondheid(szorg). In: Foets, M., Schuster, J., Stronks, K. (Eds.), Gezondheid(zorg)onderzoek onder allochtone bevolkingsgroepen. Een praktische introductie. Aksant, Amsterdam, pp. 29-50.

Goberna-Tricas, J., Viñas-Llebot, H., Palacio-Tauste, A., Galí-García, M., Paulí-Cabezas, A., Gómez-Moreno, C., 2005. Atención al embarazo en mujeres africanas inmigrantes, Percepción de las matronas de asistencia primaria. Enfermia Clinica 15 (2) 88-94.

Green, J., Thorogood, N., 2009. Qualitative Methods for Health Research. Sage Publications, London, pp. 198-203.

Guest, G., Bunce, A., Johnson, L., 2006. How many interviews are enough? An experiment with data saturation and variability. Field Methods 18 (1) 59-82. 
Boerleider, A.W., Francke, A.L., Manniën, J., Wiegers, T.A., Devillé, W.L.J.M. "A mixture of positive and negative feelings": a qualitative study of primary care midwives' experiences with 7 non-western clients living in the Netherlands. International Journal of Nursing Studies: 2013 50(12), 1658-1666

Hoang, H.T., Le, Q., Kilpatrick, S., 2009. Having a baby in the new land: a qualitative exploration of the experiences of Asian migrants in rural Tasmania, Australia. Rural and Remote Health 9 (1) 1084.

Hultsjö, S., Hjelm, K., 2005. Immigrants in emergency care: Swedish health care staff's experiences. International Nursing Review 52 (4) 276-285.

Jirwe, M., Gerrish, K., Emami, A., 2010. Student nurses' experiences of communication in cross-cultural care encounters. Scandinavian Journal of Caring Sciences 24 (3) 436-444.

Lyberg, A., Viken, B., Haruna, M., Severinsson, E., 2012. Diversity and challenges in the management of maternity care for migrant women. Journal of Nursing Management 20 (2) 287-295.

Lyons, S.M., O'Keeffe, F.M., Clarke, A.T., Staines, A., 2008. Cultural diversity in the Dublin maternity services: the experiences of maternity service providers when caring for ethnic minority women. Ethnicity and Health 13 (3) 261-276.

Manniën, J., Klomp, T., Wiegers, T., Pereboom, M., Brug, J., de Jonge, A., van der Meijde, M., Hutton, E., Schellevis, F., Spelten, E., 2012. Evaluation of primary care midwifery in the Netherlands: design and rationale of a dynamic cohort study (DELIVER). BMC Health Services Research 12, 69.

MAXQDA, Introduction. (accessed 10.01.13)http://www.maxqda.com/ download/manuals/MAX2007_intro_eng.pdf.

Murphy, K., Macleod-Clark, J., 1993. Nurses' experiences of caring for ethnic-minority clients. Journal of Advanced Nursing 18 (3) 442-450.

Murray, L., Windsor, C., Parker, E., Tewfik, O., 2010. The experiences of African women giving birth in Brisbane, Australia. Health Care for Women International 31 (5) 458-472.

$\mathrm{Ng}, \mathrm{C}$., Newbold, K.B., 2011. Health care providers' perspectives on the provision of prenatal care to immigrants. Culture, Health and Sexuality 13 (5) 561-574.

Priebe, S., Sandhu, S., Dias, S., Gaddini, A., Greacen, T., Ioannidis, E., Kluge, U., Krasnik, A., Lamkaddem, M., Lorant, V., Riera, R.P., Sarvary, A., Soares, J.J., Stankunas, M., Strassmayr, C., Wahlbeck, K., Welbel, M., Bogic, M., 2011. Good practice in health care for migrants: views and experiences of care professionals in 16 European countries. BMC Public Health 11, 187.

Puthussery, S., Twamley, K., Harding, S., Mirsky, J., Baron, M., Macfarlane, A., 2008. 'They're more like ordinary stroppy British women': attitudes and expectations of maternity care professionals to UK-born ethnic minority women. Journal of Health Services Research and Policy 13 (4) 195-201.

Ravelli, A.C., Tromp, M., Eskes, M., Droog, J.C., van der Post, J.A., Jager, K.J., Mol, B.W., Reitsma, J.B., 2011. Ethnic differences in stillbirth and early neonatal mortality in The Netherlands. Journal of Epidemiology and Community Health 65 (8) 696-701.

Reitmanova, S., Gustafson, D.L., 2008. "They can't understand it": maternity health and care needs of immigrant Muslim women in St. John's Newfoundland. Maternal and Child Health Journal 12 (1) 101-111.

Reitsma, E., Groenen, C., Fermie, M., 2007. Takenpakket eerstelijns verloskunde. (accessed 28.03.12)http://www.c3am.nl/user/file/ tvt_200803_takenpakket_eerstelijns_verloskunde_2007.pdf.

Robinson, M., Gilmartin, J., 2002. Barriers to communication between health practitioners and service users who are not fluent in English. Nurse Education Today 22 (6) 457-465.

Schippers, E.I., Veldhuijzen van Zanten-Hyllner, M.L.L.E., 2011. Invulling subsidietaakstellingen VWS. (accessed 13.04.12)http://www.rijksoverheid.nl/documentenen-publicaties/kamerstukken/2011/05/25/ invulling-subsidietaakstellingen-vws.html.

Silow-Carroll, S., Alteras, T., Stepnick, L., 2006. Patient-centered care for underserved populations: definition and best practices. (accessed 02.01.12) http://www.esresearch.org/documents 06/Overview.pdf.

Statistics Netherlands Statline, 2012. Geboorte: herkomstgroepering en leeftijd moeder. (accessed 10.09.12)http://statline.cbs.nl/StatWeb/ publication/?DM=SLNL\&PA=37884\&D1=a\&D2=0,36-42\&D3=0- 3,I\&D4=10$13 \& H D R=T \& S T B=G 2, G 1, G 3 \& V W=T$.

United Nations Population Division, 2009. International migrant stock: the 2008 revision. (accessed 02.01.12)http://esa.un.org/migration/ index.asp?panel=1. 
Boerleider, A.W., Francke, A.L., Manniën, J., Wiegers, T.A., Devillé, W.L.J.M. "A mixture of positive and negative feelings": a qualitative study of primary care midwives' experiences with
non-western clients living in the Netherlands. International Journal of Nursing Studies: 2013 . 50(12), 1658-1666

Waelput, A.J.M., Achterberg, P.W., 2007. Ethnic origin and care during pregnancy and birth: an exploration of Dutch research. RIVM, Bilthoven pp. 18, 35-37.

Wiegers, T.A., Hukkelhoven, C.W., 2010. The role of hospital midwives in the Netherlands. BMC Pregnancy and Childbirth 10, 80. 